\title{
Flow through tilt flume testing for beach slope evaluation at Chuquicamata Mine Codelco, Chile
}

\author{
B. Pirouz ATC Williams Pty Ltd, Australia \\ K. Seddon ATC Williams Pty Ltd, Australia \\ C. Pavissich ATC Williams Pty Ltd, Australia (previously Codelco-VP) \\ P. Williams Paul Williams Pty Ltd, Australia \\ J. Echevarria Codelco-VP, Chile
}

\begin{abstract}
A series of tilting (variable slope) flume tests were undertaken at the pilot plant facility at Chuquicamata copper mine in northern Chile to study the achievable tailings beach slope for different tailings solids concentrations and flowrates. The pilot plant facility was part of a prefeasibility study into upgrading the existing conventional tailings disposal facility, to a thickened tailings disposal scheme.

The tilting flume facility was included into the pilot plant trial to produce reliable data for verification of theoretical beach slope prediction models. The tests were conducted on existing tailings from the Chuquicamata plant.
\end{abstract}

A pilot size (2.5 $\mathrm{m}$ diameter) thickener was used to thicken the slurry to higher solids concentration before feeding the tilting flume. A range of different slurry flowrates (ranging from 5.5 to $18 \mathrm{~L} / \mathrm{s}$ ) and solids concentrations (ranging from 56.5 to $72.5 \%$ ) were tested.

The testing methodology, the test results and analysis, are discussed in this paper. The actual measured beach slope (based on hydrodynamics of channel flow theory) for each flowrate and slurry solids concentration are also presented.

\section{Introduction}

Codelco is undertaking a study for the upgrade of long-term tailings storage facility (TSF) at the Chuquicamata copper mine in northern Chile.

One of the options considered by Codelco is to implement thickened tailings discharge at the existing Talabre TSF. To obtain reliable data for the prefeasibility study, Codelco decided in 2010 to test the behaviour of the existing tailings using a pilot plant facility.

The pilot plant is located about $6 \mathrm{~km}$ southeast of Chuquicamata and $16 \mathrm{~km}$ to the north of Calama City, in the second Region of Chile.

The plant is fed with the current tailings from Chuquicamata plant at an average solids content of $57 \%$ using an off-take from the existing concrete flume which carries the tailings from the plant to the deposition area at Talabre TSF.

A pilot thickener (designed and operated by Outotec) with a maximum capacity of 70 tonne/day was used to produce thickened tailings at the various required concentrations.

The overall pilot plant testing included: thickening trials, tailing-conveyance and head-loss trials in a pipe loop, and thickened tailing deposition and beach slope behaviours in adjustable (tilting) and fixed slope flumes. 
ATC Williams was commissioned by Codelco to provide the design for a tilting flume as part of the pilot plant facility and to undertake a series of flume testing with different slurry flowrates and solids concentrations to evaluate the achievable tailings beach slope. This paper only covers the results of the tilting flume tests.

The tilting flume tests were conducted by ATC Williams on site within the time frame from mid-February 2011 to mid-May 2011. Figure 1 shows the overview of the pilot plant facility.

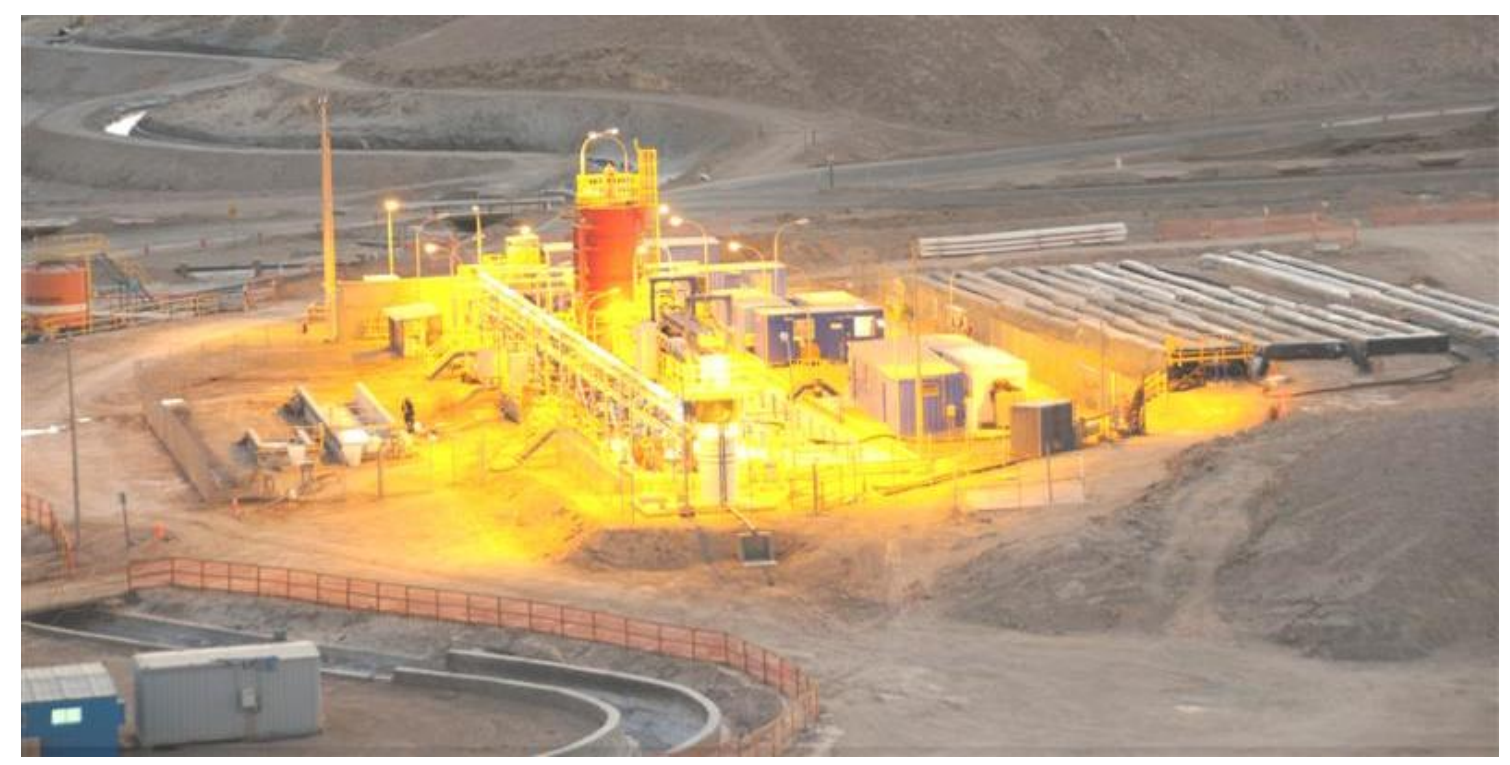

\section{Figure 1 Overview of the pilot plant facility}

The concept of evaluating the tailings beach slope using an adjustable slope flume is adopted from previous research works carried out by Pirouz et al. (2005), Pirouz and Williams (2007) and Fitton et al. (2007) which was based on the equilibrium slope model. The equilibrium slope model which was originally developed by Williams and Meynink (1986) and Williams (2001) is based on the following proposition:

The author states that for any particular tailings, the overall beach slope of the stack is determined by the limiting equilibrium channel slope which is required to create the required steady state, total transport flow condition in a self-formed channel.

\section{$2 \quad$ Tilting flume design and set-up}

The tilt flume is a designed rectangular section and has a width of one metre, a height of $0.5 \mathrm{~m}$ and a length of $10 \mathrm{~m}$, supported at upstream and downstream ends. The design dimensions for the tilting flume are based on the following considerations.

Previous experience (Pirouz et al., 2005; Pirouz and Williams, 2007) has shown that over the range of flowrate to be tested, a flume width of one metre would provide enough lateral freedom for the tailings flow to form its own beach and meandering longitudinal channel.

The concepts concerning fully developed flow, entrance region, development length and flow establishment length were all considered in the selection of the $10 \mathrm{~m}$ length for the flume. The calculation showed that the designed $10 \mathrm{~m}$ length would provide sufficient length for flow establishment and also allows the accurate measurement of beach slope inside the flume.

The design height of $0.5 \mathrm{~m}$ for sidewalls of the flume provides the required depth for the self-formed channel and beach to freely form inside the flume by deposition of solids materials in the bed.

The schematic diagram in Figure 2 shows the tilting flume facility set-up. 
A pivoting mechanism at the upstream end of the flume enables the slope of the flume to be adjusted as required by lifting or lowering the downstream end of the flume using a block and tackle system at the downstream end support.

To dissipate the excess energy and turbulence in the incoming slurry flow (through the slurry pipe and pumping system) an inlet box is designed at the upstream side of the flume to provide a plunge pool and baffling action at the upstream entrance section. The inlet box has a dimension of $1.2 \mathrm{~m}$ (width) $\times 1 \mathrm{~m}$ (length) $\times 1.2 \mathrm{~m}$ (height). The existence of this inlet box is important to ensure that the flow behaviour in the limited length of the flume (i.e. $10 \mathrm{~m}$ ) is not under the influence of the entrance condition.

Two flexible hoses are used to connect the inlet box to the rectangular flume. The inlet box is equipped with the drain valve at the bottom of the box which allows the flush-out, clean-up and drainage of the box at the end of each series of testing.

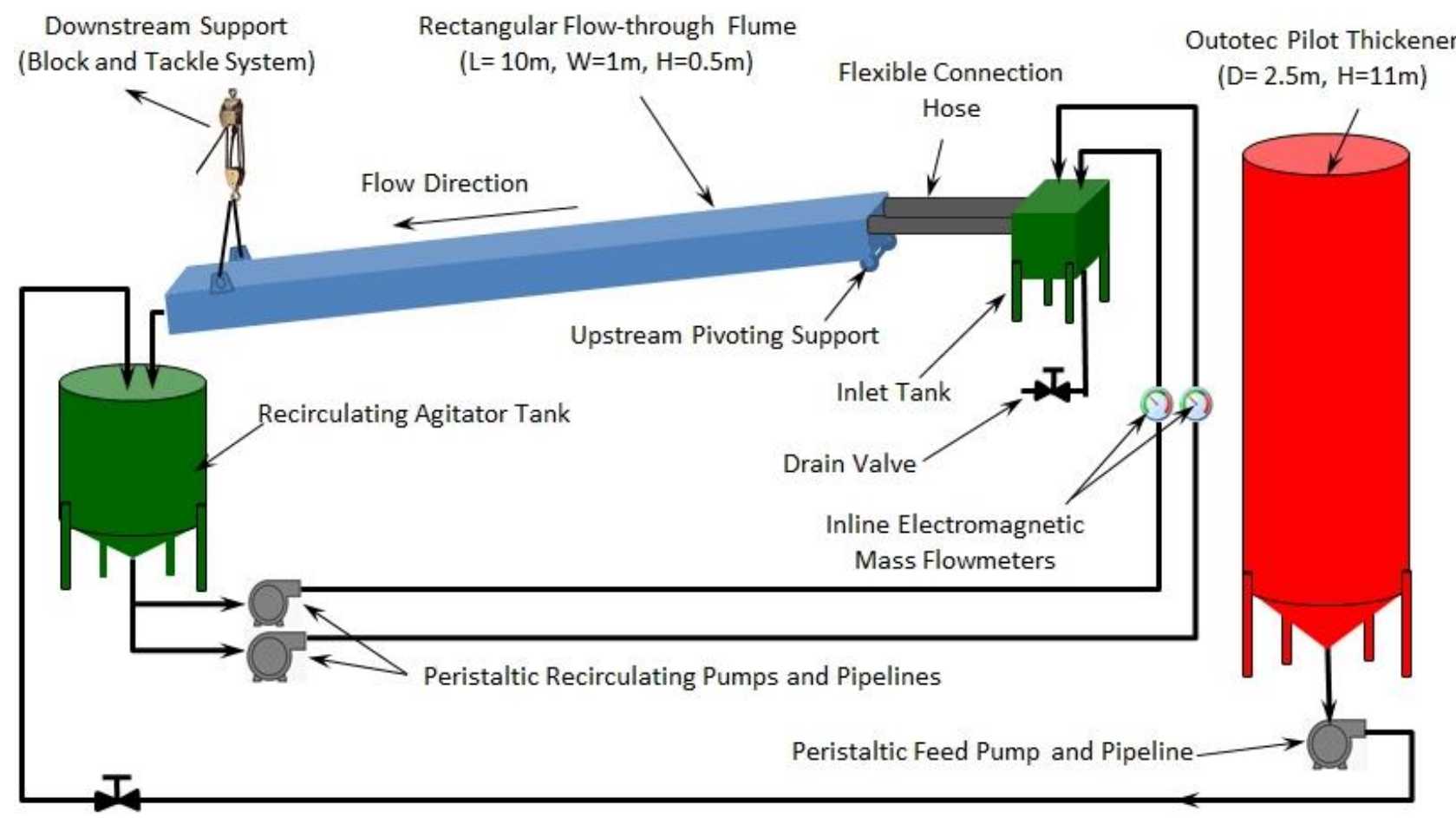

\section{Figure 2 Tilting flume facility set-up}

At a maximum throughput of 70 tonne/day the peak continuous discharge from the pilot thickener was only about $2 \mathrm{~m}^{3} / \mathrm{hr}$ or less than $1 \mathrm{~L} / \mathrm{s}$. This flowrate was considered to be totally unrepresentative of field situation. Consequently it was necessary to produce batches of thickened tailings and operate the flume on a re-circulating loop. At the design stage there was consideration and concern regarding the number of times that the loop could be run without shear degradation of solids particles (i.e. fine generation) and changes in rheology of slurry. For this reason peristaltic pumps were specified and used.

As illustrated in Figure 2 a $4 \mathrm{~m}^{3}$ storage/agitator tank (equipped with mixer) was included at the downstream end of the tilting flume. At the beginning of each series of tests, the agitator tank is filled with $4 \mathrm{~m}^{3}$ of slurry from the pilot thickener using a peristaltic pump. The inlet valve from the pilot plant thickener is then closed-off to isolate the tilting flume facility from the rest of the plant.

During the test runs the tailings are recirculated through the tilting flume using the two variable speed peristaltic pumps and two $90 \mathrm{~mm}$ diameter HDPE re-circulating pipelines. The two recirculation lines from the agitator tank are equipped with inline electromagnetic mass flowmeters. The variable speed control system of the peristaltic pumps allows accurate adjustment of flowrate between a minimum of $2.5 \mathrm{~L} / \mathrm{s}$ to a maximum of $20 \mathrm{~L} / \mathrm{s}$. 
The outflow from the end of the tilting flume is directly discharged into the agitator tank where it is remixed and recirculated through the system.

The recirculation of tailings within the system and the applied sheared to the tailings by the pumping system simulates the sheared condition at the end of the discharge pipe in real size TSF.

The flume testing was carried out in two stages. At the first stage the development of self-formed tailings channel was allowed within the full rectangular flume section. For the second stage two different sizes of HDPE half-pipe sections with average internal diameters of $228 \mathrm{~mm}$ and $326 \mathrm{~mm}$ HDPE were installed inside the rectangular flume.

The inside wall of the HDPE pipes was coated with relatively coarse sand with a nominal particle size of $1.18 \mathrm{~mm}$. The objective is to have the sand coarser than the tailings particles so that after the first run of tailings flow through the flume, the tailings particles become trapped in the interstices of the sand lining and form a surface that is very close to tailings roughness.

The two HDPE pipes are supported by a timber frame system which allows the two half-pipes to be lifted in and out of the rectangular flume using a block and tackles chain system at the downstream and upstream ends. The overview of the tilting flume is seen in Figure 3.

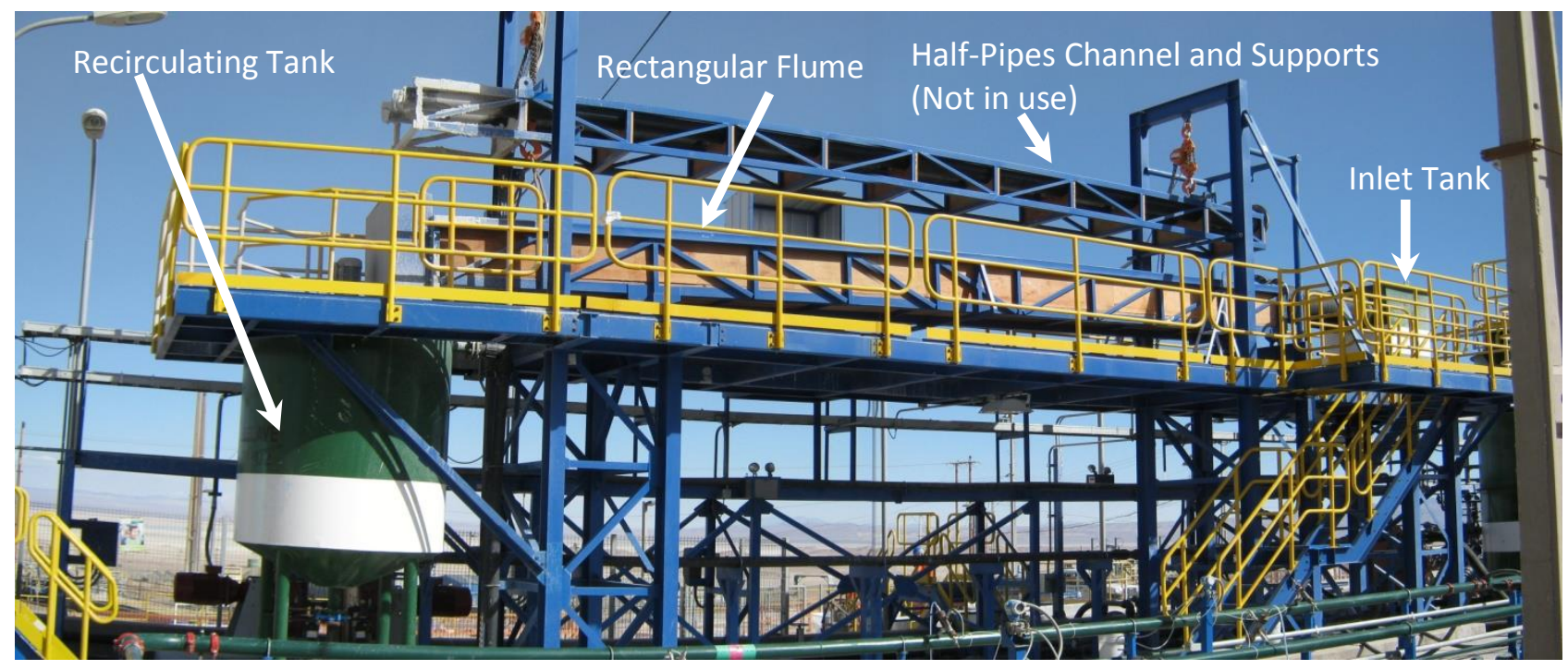

Figure 3 General view of the tilting flume facility

\section{$3 \quad$ Tilting flume testing methodology}

Two different types of tests are undertaken in the tilting flume:

1. Self-formed channel tests

2. Half-pipe channel tests

\subsection{Self-formed channel in rectangular flume}

For this stage of the tests the rectangular flume is set to a horizontal slope or any slope judged to be flatter than the equilibrium slope (which will be subsequently confirmed by the test) and the slurry flow of a known solids concentration and flowrate is introduced into the flume from the upstream inlet box.

The slurry is allowed to build up its own beach and channel of self-determined shape and slope by depositing solids materials on the bed.

The build-up of the tailings inside the rectangular flume is continuously checked until the deposition and build-up of the bed in the flume reaches an equilibrium condition. After the beach is developed and equilibrium slope channelised flow is well established in the flume, i.e. the tailings has built up within the 
flume to a stable slope where neither further build-up (change in slope) or erosion occurs, the flow characteristics i.e. self-formed channel dimensions, surface profile along the channel, channel slope and channel width and shape are measured and recorded. Samples are also taken for particle size distribution and rheology test.

During this series of tests (depending on the flowrate), about $2 \mathrm{~m}^{3}$ of the total available tailings volume in the system were typically used for deposition on the bed and channel formation while the rest of the tailings volume were available for recirculation in the system.

Figure 4 shows the self-formed channel within the rectangular flume.

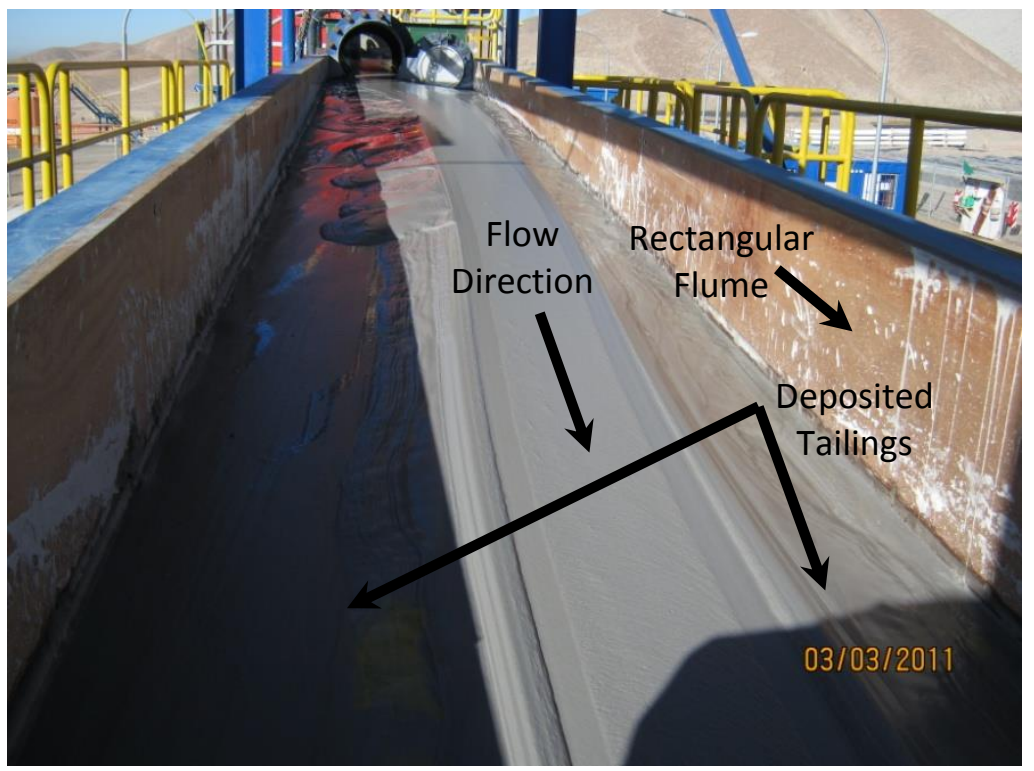

Figure 4 Self-formed channel in rectangular flume

\subsection{Semi-circular half-pipe channels}

For this series of tests the two half-pipe sections are installed inside the rectangular flume. At the start of each test the slope of the flume (half-pipe channel) is set initially to a relatively steep slope and the tailings with a known solids concentration and flowrate is introduced into the flume from the upstream inlet box. The initial steep slope setting for the half-pipe channel causes fast moving (non-depositioning) flow to occur in the half-pipe channel. It should be noted that during the tests the half-pipe section was not generally flowing full and therefore the actual channel section was a segment of a circle with depth variable depending of the flowrate.

The channel slope is then gradually reduced (by adjustment of the flume slope from the downstream end) until deposition along the channel just started to occur. The surface profile of the flow in the half-pipe channel is continuously checked for deposition of solids (raise in the surface with time) following each change in the slope. By this mechanism the channel slope for which a steady uniform flow develops within the channel (with no further deposition on the bed, i.e. the equilibrium slope) is found. At this condition the flow characteristics including depth of flow, surface profile along the channel, velocity profile with depth, density profile with depth and the equilibrium slope are measured. Figure 5 shows the half-pipe channel flow tests.

The half-pipe channel tests at the equilibrium slope condition are of particular interest and an extremely important part of the tilting flume testing due to the following reasons:

- Because the shape of the channel is known for these tests, the data collected from half-pipe channel tests are very useful in the development (or verification) of the theoretical models for head loss calculation in open channel flow of slurry. 
- Because of the rigid channel boundaries, the measurement of velocity and density profiles with depth - by entering the probes into the flow - is possible. This does not cause any instability in the flow or damages to the channel walls as is the case for self-formed channel.

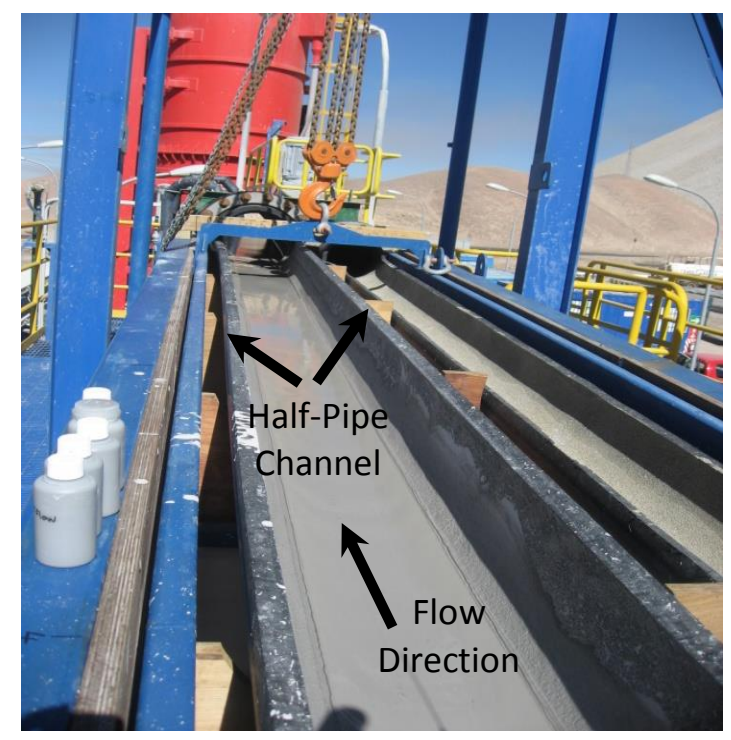

\section{Figure 5 Half-pipe channel flow test}

During the test runs samples were taken for particle size distribution analysis from top and bottom of the flow under the equilibrium slope condition at three different sections along the flume, the upstream end of the flume, the middle of the flume (approximately $5 \mathrm{~m}$ from the entrance) and at the downstream end of the flume. Samples were also taken for rheology and solids concentration checking during the test. Figure 6 shows the range of solids concentrations and flowrates used in the tilting flume tests.

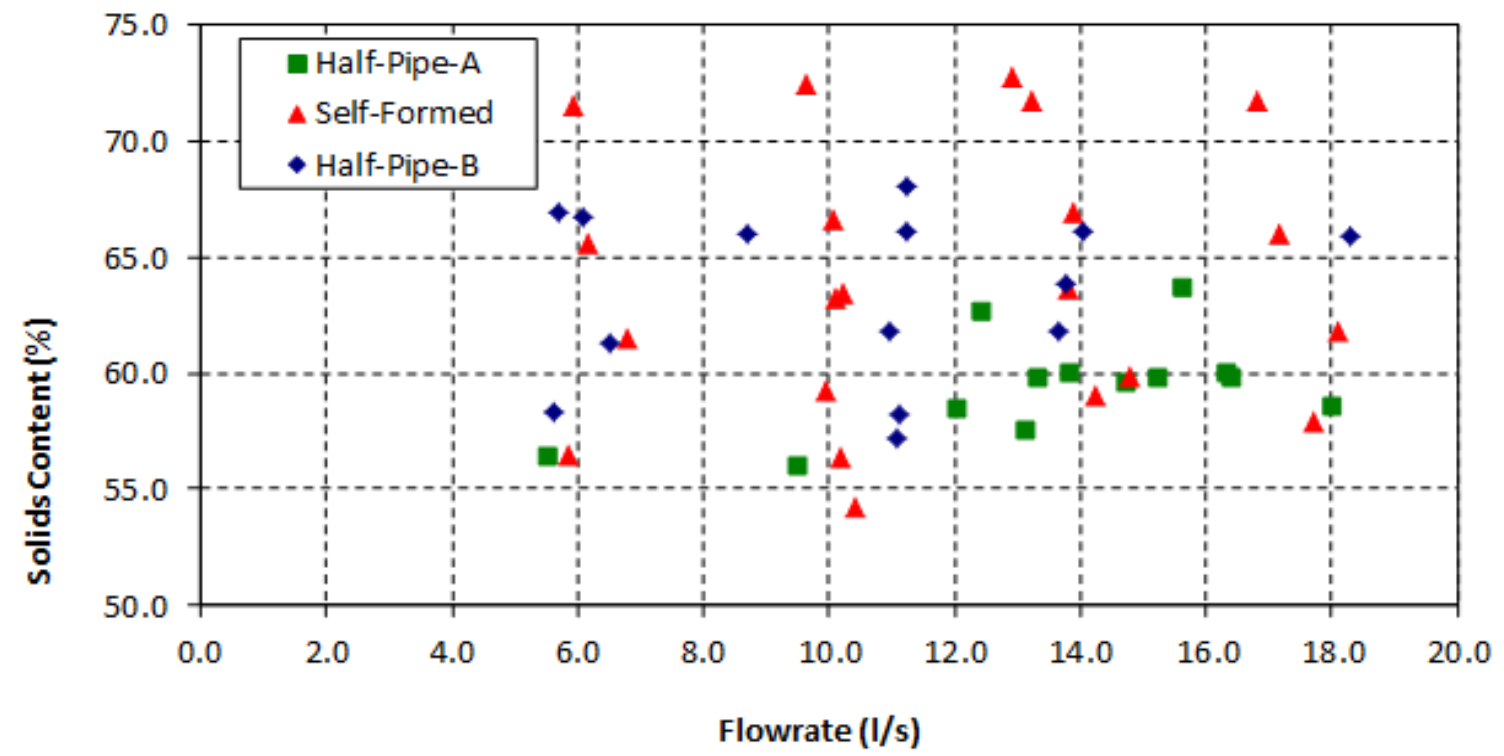

Figure 6 Range of flowrate and solids slurry content for the tilting flume tests

\section{$4 \quad$ Tests results}

\subsection{Flow condition and behaviour}

The visual observation from the flow condition in both self-formed channel and half-pipe channel tests showed that the flow condition in the channel could not be simply considered as a homogeneous laminar 
or turbulent flow but instead a 'plug flow zone' appeared at the centreline of the channel with 'shearing zones' close to the stationary boundaries.

The plug flow and shear zone in self-formed channel tests are shown in Figure 7. The shearing zone is subjected to the high shear rate applied to the slurry layers due to the relatively homogeneous moving plug at one side and stationary boundaries (channel wall) at the other side.

It seems that the shearing zone acts as a sub-layer close to the boundaries which carries the rest of the slurry flow in the central plug. So the major part of the flow moves in the plug without sensing any effect from the stationary channel boundaries. The plug is simply the region of the flow where the applied shear to the slurry particles is smaller than the yield stress of the slurry.

Based on the observations and the recorded parameters during the tests, it is believed that the slurry particles within the central plug are carried by the shear zone on an essentially constant velocity, i.e. the same velocity as the inner layer of the shearing zone (which is the maximum velocity in the channel) with no significant particle movement relative to each other in the direction of the flow. In other words the velocity gradient within the plug approaches zero.

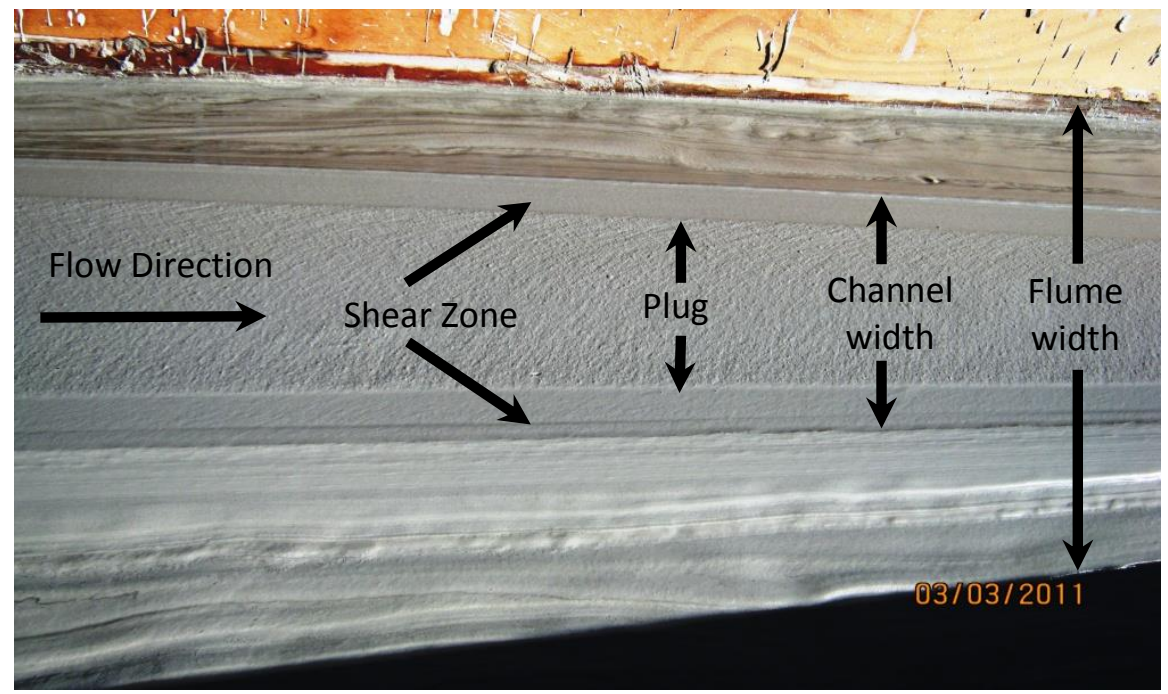

\section{Figure 7 Shear zone and plug flow in channelised tailings flow}

The existence of the 'pPlug' and 'sShear zone' in the pipe flow of non-Newtonian fluids has previously been recognised and reported by other researchers and the theoretical approach to analysis this type of nonNewtonian pipe flow is well known. One of the earliest publications on the subject is the paper by Hedstrom (1952). The analytical background on the subject has been reviewed by Slatter (2011). But to the knowledge of the author of this paper the plug formation in open channel flow of non-Newtonian slurries has not been reported previously in any other research works. Therefore there is a very limited knowledge available about the subject and the methodology to analyse the open channel flow of this type.

The test results show that the relative width of the plug increases with increase in slurry solids concentration (yield stress). This continues to a point when the shear sub-layer approaches to zero thickness and plug width becomes equal to the channel width. In this situation the entire channel flows in a very slow moving laminar regime. Figure 8 shows the results from one of the self-formed channel tests when the slurry was very thick $(72.5 \%)$ and the plug width was equal to the channel width. 


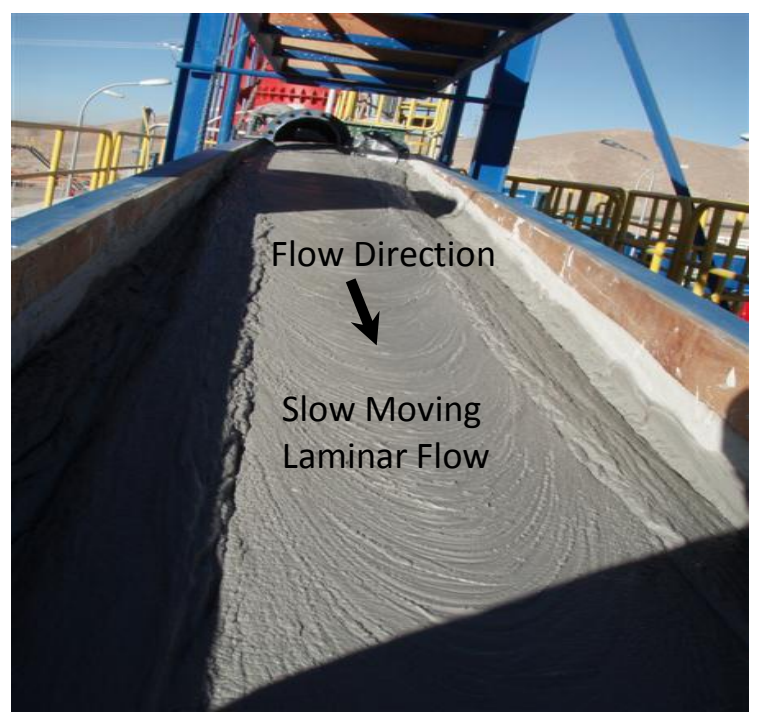

Figure 8 Slow moving laminar flow at high slurry solids content

\subsection{Self-formed channel in rectangular flume}

During the self-formed channel tests (after the equilibrium slope is reached) the flow surface profiles (along the flume length) were recorded. The slope of flow surface profile at the middle section of the flume (typically between stations $3 \mathrm{~m}$ to $8 \mathrm{~m}$ from the flume inlet) which is not affected by the entrance and exit regions has been reported as the beach slope.

The surface velocity of the flow at the centre of the channel (plug flow) was also measured by recording the travel time of a small floating chip on the surface of the flow between two reference points along the channel. Other typical parameters recorded for each test include the slurry flowrate, slurry solids concentration, channel dimensions, channel and the central plug width, surface velocity, rheology and the achieved equilibrium slope. The recorded data for each test are reported in Table 1.

As it is seen in Table 1 the rheology behaviour of the slurry at each test is presented in terms of the Herschel-Bulkley model parameters. Herschel-Bulkley model is described here and is well accepted by most slurry experts for describing the rheology of yield pseuodoplastics (shear thinning) or yield dilatant (shear thickening) materials with low to moderate concentration of solids.

$$
\tau=\tau_{y}+k \propto \&
$$

Where:

$$
\begin{aligned}
\tau & =\text { shear stress }(\mathrm{Pa}) . \\
\tau_{y} & =\text { slurry yield stress }(\mathrm{Pa}) . \\
\dot{\gamma} & =\text { shear rate }\left(\mathrm{s}^{-1}\right) . \\
k & =\text { slurry consistency factor }\left(\mathrm{Pa}_{\mathrm{S}} \mathrm{s}^{n}\right) . \\
n & =\text { slurry behaviour index }(\text { smaller than unity). }
\end{aligned}
$$


Table 1 Summary of tilt flume test results for self-formed channel flow

\begin{tabular}{|c|c|c|c|c|c|c|c|c|c|c|c|c|}
\hline \multirow{3}{*}{ Test } & \multirow{3}{*}{$\begin{array}{c}\text { Flowrate } \\
Q(1 / s)\end{array}$} & \multirow{3}{*}{$\begin{array}{l}\text { Solids } \\
\text { Content } \\
\text { Cw (\%) }\end{array}$} & \multirow{3}{*}{$\begin{array}{c}\text { Channel } \\
\text { Depth* } \\
(\mathrm{mm})\end{array}$} & \multirow{3}{*}{$\begin{array}{l}\text { Channel } \\
\text { Width } \\
\text { (mm) }\end{array}$} & \multirow{3}{*}{$\begin{array}{c}\text { Plug } \\
\text { Width } \\
(\mathrm{mm})\end{array}$} & \multirow{3}{*}{$\begin{array}{l}\text { Flow } \\
\text { Area* } \\
\left(\mathrm{m}^{2}\right)\end{array}$} & \multirow{3}{*}{$\begin{array}{c}\text { Surface } \\
\text { Velocity } \\
(\mathrm{m} / \mathrm{s})\end{array}$} & \multicolumn{3}{|c|}{ Herschel-Bulkley Model } & \multirow{2}{*}{\multicolumn{2}{|c|}{$\tau_{1 \text { OO }}^{\text {Slope }}(\%)$}} \\
\hline & & & & & & & & \multicolumn{3}{|c|}{$\tau=\tau_{y}+k \chi \&$} & & \\
\hline & & & & & & & & $T_{y}(\mathrm{~Pa})$ & k & $\mathbf{n}$ & $(\mathrm{Pa})$ & \\
\hline $14 \mathrm{~A}$ & 6.80 & 61.50 & --- & 405 & --- & --- & --- & 6.5 & 0.865 & 0.457 & 14 & --- \\
\hline 15 & 10.43 & 54.20 & --- & 710 & --- & --- & --- & 2.1 & 0.293 & 0.487 & 5 & --- \\
\hline 16 & 10.20 & 56.34 & --- & 290 & --- & --- & 1.49 & 6.8 & 0.770 & 0.469 & 14 & --- \\
\hline 17 & 14.25 & 58.99 & --- & 360 & --- & --- & 1.22 & 8.1 & 0.987 & 0.453 & 15.5 & 4.6 \\
\hline 18 & 18.10 & 61.81 & --- & 370 & --- & --- & 0.99 & 12.0 & 1.528 & 0.454 & 24 & 4.6 \\
\hline 19 & 5.95 & 71.57 & --- & 264 & 195 & --- & 0.49 & 25.9 & 5.990 & 0.425 & 68 & 8.6 \\
\hline 20 & 9.64 & 72.50 & --- & 460 & 460 & --- & 0.22 & 74.6 & 16.690 & 0.380 & 170 & 9.7 \\
\hline 21 & 13.22 & 71.76 & --- & 515 & 425 & --- & 0.28 & 101.2 & 15.170 & 0.389 & 191 & 9.7 \\
\hline 22 & 12.91 & 72.77 & --- & 480 & 435 & --- & 0.23 & --- & --- & --- & --- & 9.2 \\
\hline 23 & 16.80 & 71.79 & --- & 350 & 315 & --- & 0.49 & 82.4 & 12.250 & 0.398 & 160 & 8.4 \\
\hline 24 & 10.21 & 63.50 & --- & 340 & 230 & --- & 0.82 & --- & --- & --- & --- & 5.7 \\
\hline 25 & 10.09 & 63.25 & --- & 210 & 130 & --- & 1.74 & 15.5 & 1.540 & 0.478 & 29.5 & 5.0 \\
\hline 26 & 13.80 & 63.70 & --- & 355 & 255 & --- & 0.83 & 17.5 & 0.937 & 0.524 & 28 & 5.1 \\
\hline 27 & 17.70 & 57.91 & --- & 537 & 455 & --- & 1.04 & 8.5 & 0.543 & 0.493 & 13.5 & 5.5 \\
\hline $27 \mathrm{~A}$ & 14.79 & 59.90 & --- & 430 & 360 & --- & 0.74 & 13.7 & 0.754 & 0.530 & 21.5 & --- \\
\hline 28 & 9.97 & 59.29 & --- & 400 & 300 & --- & 0.89 & 12.0 & 0.593 & 0.544 & 19 & 5.7 \\
\hline 29 & 5.84 & 56.43 & --- & 315 & 220 & --- & 1.05 & 7.6 & 0.636 & 0.477 & 13 & 6.1 \\
\hline 30 & 17.19 & 66.03 & --- & 375 & 290 & --- & 0.76 & 14.7 & 1.894 & 0.452 & 30 & 5.0 \\
\hline 31 & 13.90 & 66.91 & --- & 355 & 275 & --- & 0.66 & 17.6 & 1.901 & 0.462 & 33.5 & 5.0 \\
\hline 32 & 10.07 & 66.60 & --- & 320 & 250 & --- & 0.58 & 21.3 & 2.009 & 0.458 & 37.5 & 5.1 \\
\hline 33 & 6.15 & 65.61 & --- & 280 & 200 & --- & 0.47 & 11.5 & 1.363 & 0.450 & 22 & 5.9 \\
\hline
\end{tabular}

*The measurement of the depth of channel and calculation of the flow area were not possible in this method.

\subsection{Semi-circular half-pipe channels}

The half-pipe tests were conducted in two different time periods from 16 to 21 February 2011 and from 23 April to 8 May 2011 (before and after the self-formed channel tests).

The data collected during the half-pipe channel tests are summarised in Table 2. 
Table 2 Summary of tilt flume test results for half-pipe channel flow

\begin{tabular}{|c|c|c|c|c|c|c|c|c|c|c|c|c|}
\hline \multirow{3}{*}{ Test } & \multirow{3}{*}{$\begin{array}{c}\text { Flowrate } \\
Q(1 / s)\end{array}$} & \multirow{3}{*}{$\begin{array}{c}\text { Solids } \\
\text { Content } \\
(\%)\end{array}$} & \multirow{3}{*}{$\begin{array}{c}\text { Channel } \\
\text { Depth } \\
(\mathrm{mm})\end{array}$} & \multirow{3}{*}{$\begin{array}{l}\text { Channel } \\
\text { Width } \\
\text { (mm) }\end{array}$} & \multirow{3}{*}{$\begin{array}{c}\text { Plug } \\
\text { Width } \\
(\mathrm{mm})\end{array}$} & \multirow{3}{*}{$\begin{array}{l}\text { Flow } \\
\text { Area } \\
\left(\mathrm{m}^{2}\right)\end{array}$} & \multirow{3}{*}{$\begin{array}{c}\text { Surface } \\
\text { Velocity } \\
\text { (m/s) }\end{array}$} & \multicolumn{3}{|c|}{ Herschel-Bulkley Model } & \multirow{2}{*}{\multicolumn{2}{|c|}{$\tau_{1 \text { OO }}^{\text {Slope }}(\%)$}} \\
\hline & & & & & & & & \multicolumn{3}{|c|}{$\tau=\tau_{y}+k x \&$} & & \\
\hline & & & & & & & & $\mathrm{T}_{\mathrm{y}}(\mathrm{Pa})$ & k & $\mathbf{n}$ & $(\mathrm{Pa})$ & \\
\hline 1 & 12.40 & 62.70 & 71.0 & 269 & --- & 0.01342 & --- & 13.9 & 1.230 & 0.477 & 25 & 5.0 \\
\hline 2 & 15.60 & 63.80 & 81.5 & 282 & --- & 0.01632 & --- & 15.5 & 2.012 & 0.440 & 32 & 4.8 \\
\hline $3 \mathrm{~A}$ & 5.50 & 56.50 & 41.5 & 217 & --- & 0.00618 & --- & 3.6 & 0.858 & 0.379 & 8 & 7.9 \\
\hline 4 & 16.40 & 59.90 & 61.0 & 254 & --- & 0.01080 & --- & 7.3 & 1.220 & 0.415 & 15 & 5.4 \\
\hline 5 & 13.10 & 57.60 & 52.5 & 240 & --- & 0.00870 & --- & 5.0 & 0.954 & 0.429 & 12 & 5.2 \\
\hline 6 & 9.50 & 56.10 & 49.0 & 233 & --- & 0.00787 & --- & 5.2 & 1.446 & 0.375 & 13.5 & 5.3 \\
\hline 7 & 18.00 & 58.60 & 71.0 & 269 & --- & 0.01342 & --- & 5.0 & 0.978 & 0.421 & 12 & 4.8 \\
\hline 8 & 12.00 & 58.50 & 58.5 & 250 & --- & 0.01017 & --- & 4.6 & 1.166 & 0.406 & 12 & 4.9 \\
\hline 9 & 16.30 & 60.10 & 69.0 & 266 & --- & 0.01289 & --- & 5.8 & 0.735 & 0.455 & 12 & 4.8 \\
\hline 10 & 15.20 & 59.90 & 69.0 & 266 & --- & 0.01289 & --- & --- & --- & --- & --- & 4.8 \\
\hline 11 & 14.70 & 59.70 & 64.5 & 260 & --- & 0.01170 & --- & --- & --- & --- & --- & 4.9 \\
\hline 12 & 13.80 & 60.10 & 65.5 & 261 & --- & 0.01196 & --- & --- & --- & --- & --- & 4.9 \\
\hline 13 & 13.30 & 59.90 & 61.0 & 254 & --- & 0.01080 & --- & 9.0 & 0.805 & 0.489 & 17 & 4.8 \\
\hline 34 & 8.71 & 65.97 & 79.0 & 279 & --- & 0.01562 & --- & 16.6 & 1.398 & 0.524 & 32 & 5.4 \\
\hline 35 & 14.05 & 66.10 & 86.0 & 287 & --- & 0.01760 & 1.22 & 18.0 & 1.666 & 0.510 & 35 & 5.1 \\
\hline 36 & 18.29 & 65.93 & 100.0 & 301 & --- & 0.02117 & 1.38 & 20.4 & 1.812 & 0.491 & 38 & 5.2 \\
\hline 37 & 6.10 & 66.73 & 60.0 & 260 & 205 & 0.01055 & 0.48 & 24.5 & 2.521 & 0.478 & 47 & 5.5 \\
\hline 38 & 6.52 & 61.25 & 41.0 & 198 & 110 & 0.00608 & 1.73 & 6.0 & 0.759 & 0.485 & 13 & 5.5 \\
\hline 39 & 13.79 & 63.86 & 61.0 & 254 & --- & 0.01080 & 1.70 & 10.1 & 0.596 & 0.573 & 19 & 5.0 \\
\hline 40 & 13.67 & 61.83 & 63.0 & 242 & 142 & 0.01131 & 1.78 & 8.2 & 0.485 & 0.536 & 14 & 5.2 \\
\hline 41 & 10.98 & 61.78 & 52.0 & 230 & 110 & 0.00858 & 1.71 & 9.1 & 0.56 & 0.55 & 16 & 5.5 \\
\hline 42 & 11.25 & 66.11 & 65.0 & 244 & 170 & 0.01183 & 1.29 & 14.6 & 1.409 & 0.496 & 28 & 5.7 \\
\hline 43 & 5.69 & 66.99 & 56.0 & 246 & --- & 0.00955 & --- & 19.2 & 1.437 & 0.507 & 34 & 6.4 \\
\hline 44 & 11.23 & 68.04 & 73.0 & 246 & 190 & 0.01396 & --- & 24.1 & 2.181 & 0.491 & 45 & 6.1 \\
\hline 45 & 11.10 & 57.24 & 47.0 & 229 & --- & 0.00741 & 2.38 & 3.7 & 0.803 & 0.408 & 9 & 5.2 \\
\hline $45 \mathrm{~A}$ & 11.11 & 58.19 & 44.0 & 223 & --- & 0.00674 & --- & 4.1 & 0.747 & 0.419 & 9 & 5.5 \\
\hline 46 & 5.63 & 58.27 & 35.0 & 202 & --- & 0.00482 & 1.74 & 4.7 & 0.675 & 0.441 & 9.5 & 6.0 \\
\hline
\end{tabular}

\subsection{Rheological characteristics of the slurry}

The rheological characteristic of the slurry for each test were determined from the samples taken from the exit of the flume at the start and end of each test. The rheology of the samples was determined on site using a bob in cup type Thermo HAAKE VT550 rheometer.

The Herschel-Bulkley model fit parameters, the tangent intercept stress at shear rate of $100 \mathrm{~s}^{-1}$ and $\tau_{100}$ which is shear stress at a shear rate of $100 \mathrm{~s}^{-1}$ for each sample are presented in Tables 1 and 2. The variation of $\tau_{100}$ with slurry solids concentration is presented in Figure 9.

The test results show that in all of the tests the slurry sample taken at the end of the test had a marginally higher solids content and hence a typically higher rheology than the sample taken at the start of the test. This was realised to be due to the surface evaporation from recirculating tailings in the flume during the 
test which resulted in a higher solids content at the end of the test. The overall variation was small and was not considered to be a significant influence on the results.

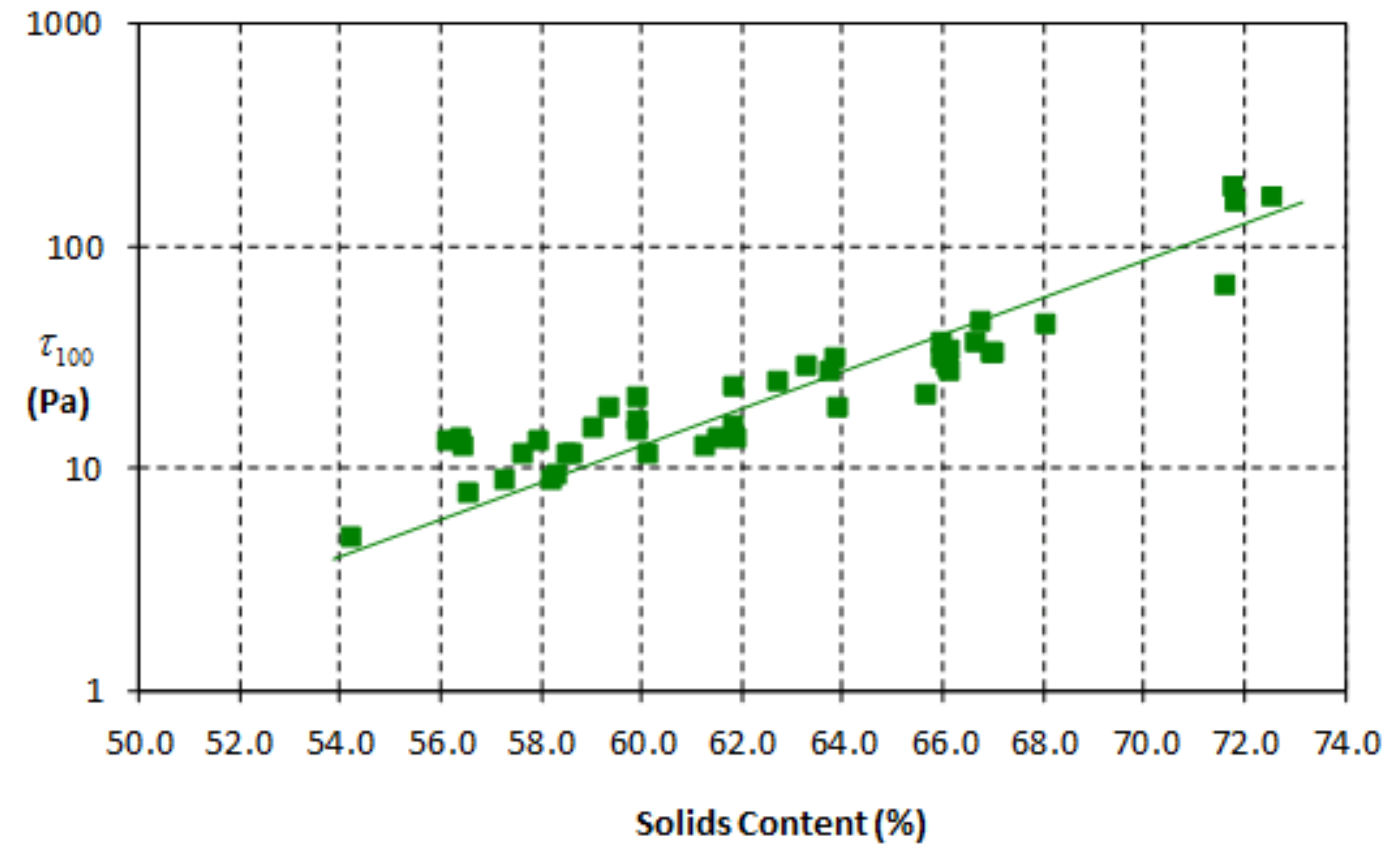

\section{Figure 9 Variation of $\tau_{100}$ with slurry solids content}

The particle size distribution (PSD) analysis of the slurry samples taken at different times during the tests confirmed that the observed small changes in slurry rheology were not due to generation of fines as a result of recirculation of the slurry in the flume.

It is true that recirculation results in breakdown of flocculant structure in the slurry which will affect the theology (reduces the rheology) but the results actually show that the recirculation and pumping (using peristaltic pumps) had negligible effect on the fines generation. This is discussed in the following section.

\subsection{Particle size distribution analysis}

To investigate the variation of particle size distribution of the tailings with time and also the effect of recirculation of the slurry in the flume using the peristaltic pumps on PSD, slurry samples were taken for PSD analysis during the tests.

Figure 10 shows the variation of the tailings PSD - received from the pilot plant thickener - with time. The PSD analysis shown in this figure relates to average samples taken from the exit of the flume at the start and end of the tests.

It should be noted that the tailings were replaced with fresh tailings from the pilot thickener at the start of tests $19,24,30,34,38,42$ and 45.

As it is seen in Figure 10 that the PSD of received tailings varied slightly over the period when the pilot plant was under operation but the plotted data show that recirculation of tailings in the flume using peristaltic pumps had negligible effect in breaking the particles and generation of fines. The slurry PSD has remained almost unchanged during each set of the tests.

Samples were also taken for PSD analysis from top and bottom of the flow at different locations along the length of the flume during the tests. The purpose of these sampling was to investigate the possible segregation of the coarse particles during the transport of tailings in the channel.

The review of the results shows that although in some of the tests the tailings at the base of the channel had slightly coarser grading than the slurry at the surface of the flow, the results do not indicate any 
noticeable segregation of coarse particles with depth or particles sorting during the transport of the tailings in the flume. In general it can be concluded that at equilibrium slope, the flow of tailings slurry in selfformed and half-pipe channels could be considered as 'total transport flow' with no segregation or particles sorting.

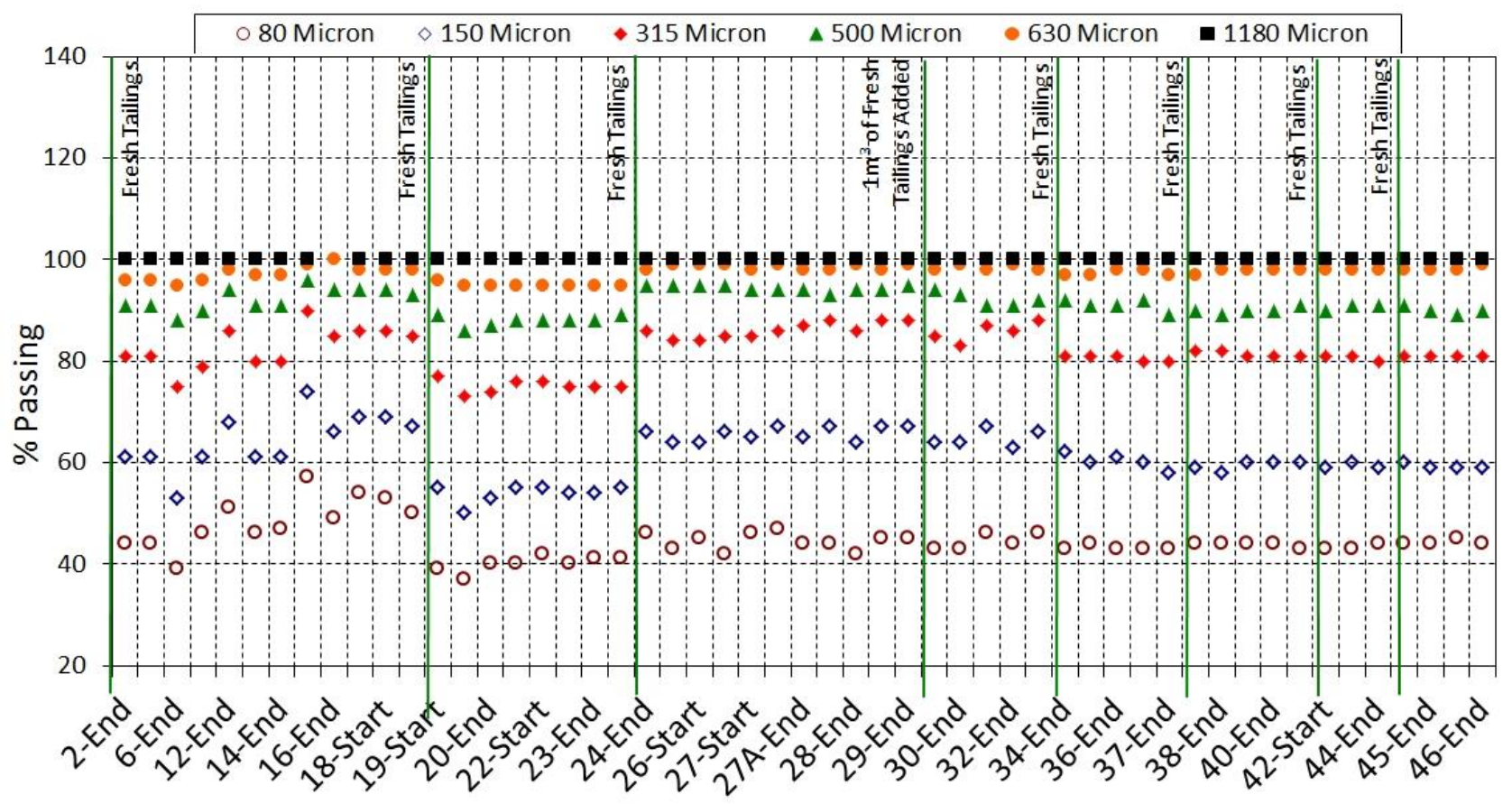

\section{Figure 10 Variation of tailings PSD throughout the test works}

\subsection{Velocity and density profiles}

The measurement of velocity profile with depth during the tests was possible by using an immersible E-30 type programmable electromagnetic sensor and control unit developed and manufactured by Delft Hydraulics.

The solids concentration profile with depth was measured with a conductivity type concentration meter probe also developed and manufactured by Delft Hydraulics. The rod shaped concentration probe had a tip dimension of $2 \times 10 \times 10 \mathrm{~mm}$.

The details of the velocity and density measurement techniques and instrumentation have been described in the paper by Pirouz et al. (2005).

A typical set of velocity and density profile recorded during the tests is presented in Figure 11. Both profiles are recorded at the centreline of the channel. In order to make sure that the flow characteristics were not affected by the entrance and inlet condition, the velocity and density profiles were recorded at four metres downstream of the flume inlet.

It should be noted that the measured points in the density profiles presented in Figure 11 are relative numbers and should only be interpreted as the relative variation of density with depth and not the absolute value of solids concentration at the point.

A review of the recorded velocity profiles shows that all of the profiles have similar shape indicating that the slurry layers move with the same and almost constant velocity to a certain depth from the surface (the plug region) and then after that depth the velocity profiles starts to be affected by the stationary boundaries. Below that depth (the shear zone region) the velocity gradually reduces as it gets closer to the stationary boundaries. 

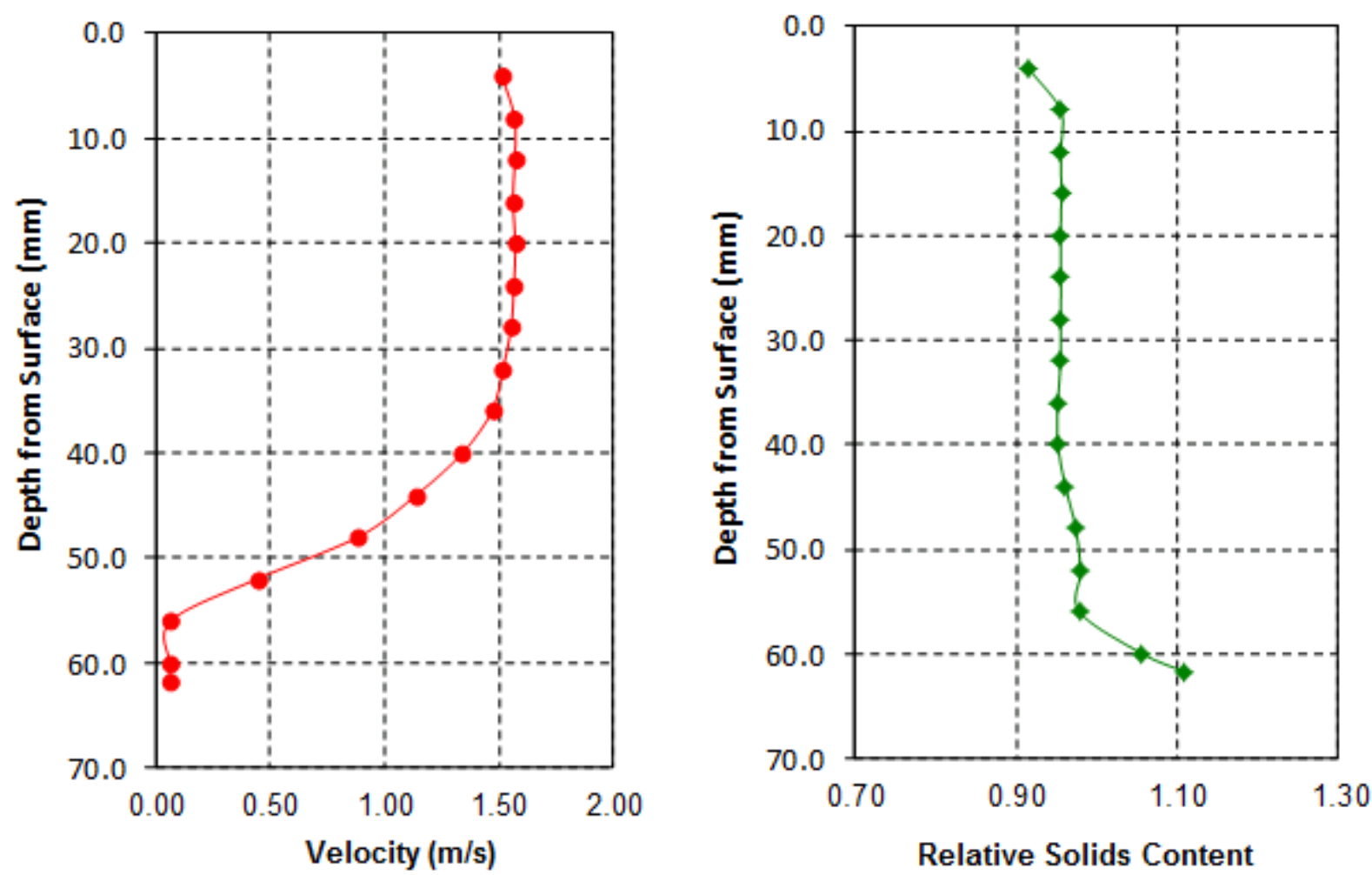

Figure 11 Typical recorded velocity and density profiles (Test $39, \mathrm{Q}=13 \mathrm{~L} / \mathrm{s}, \mathrm{Cw}=$ $63.9 \%)$

The recorded velocity profiles all confirm the existence of a plug zone and the shear zone in the slurry flows. From the recorded density profiles the distinction of the boundary between the plug and the shear zone is very difficult. Most of the density profiles show that the density remains almost constant for the majority of the depth of the flow and then close to the bed the density suddenly increases confirming a bed layer formation right at the boundary.

\subsection{Equilibrium channel slope}

The last column in Tables 1 and 2 represents the recorded equilibrium channel slope for each test. The results show that for the range of slurry flowrates and solids concentration tested the equilibrium slope varied between 4.6 to $9.7 \%$.

Based on equilibrium slope model, the beach slope is believed to be a function of many parameters such as slurry flowrate, rheology, solids concentration, PSD, etc. Some of these parameters are not independent from the others but the study of the tailings beach slope needs to consider the combined effects of all these parameters.

The two obviously independent parameters influencing the beach slope are the slurry solids concentration and the slurry flowrate.

The variation of equilibrium slope (beach slope) with slurry solids concentration is presented in Figure 12. The use of solids concentration in this figure is essentially a substitution for rheology of slurry (see Figure 9). The effect of slurry flowrate on equilibrium slope (beach slope) is shown in Figure 13 . The combined effect of flowrate and solids concentration make it hard to recognise a pattern or trend on the results presented in Figures 12 and 13.

The data suggest that the equilibrium slope is proportional to solids concentration/rheology and inversely proportional to flowrate. The collected data have been re-plotted in Figure 14 to show the combined effects of the influencing parameters. Figure 14 shows the variation of equilibrium slope with yield stress to 
flowrate ratio (normalised yield stress $\tau_{100} / Q$ ). As it is seen, this figure represents the combined effect of the two influencing parameters on equilibrium slope.

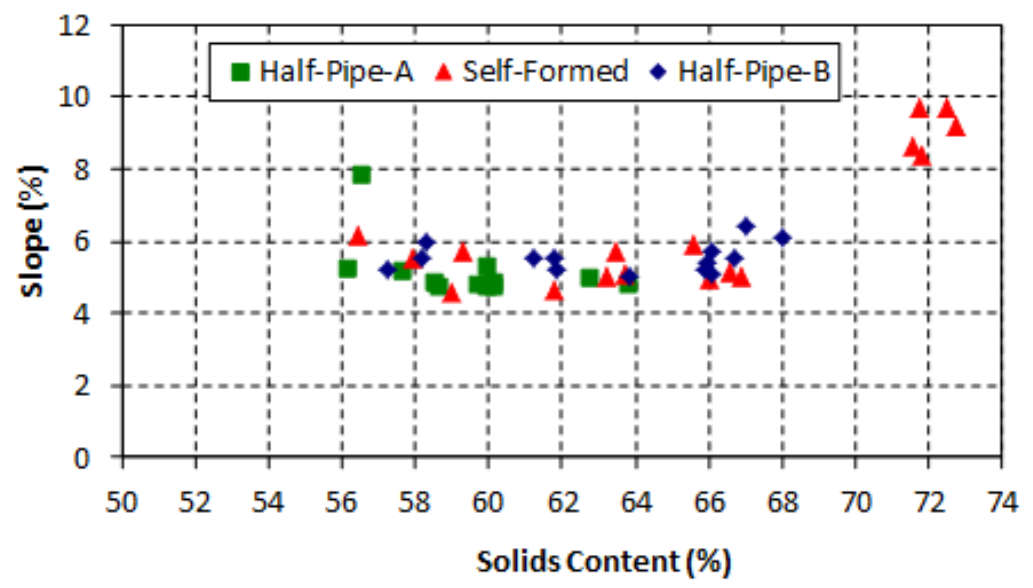

Figure 12 Variation of equilibrium slope with slurry solids concentration

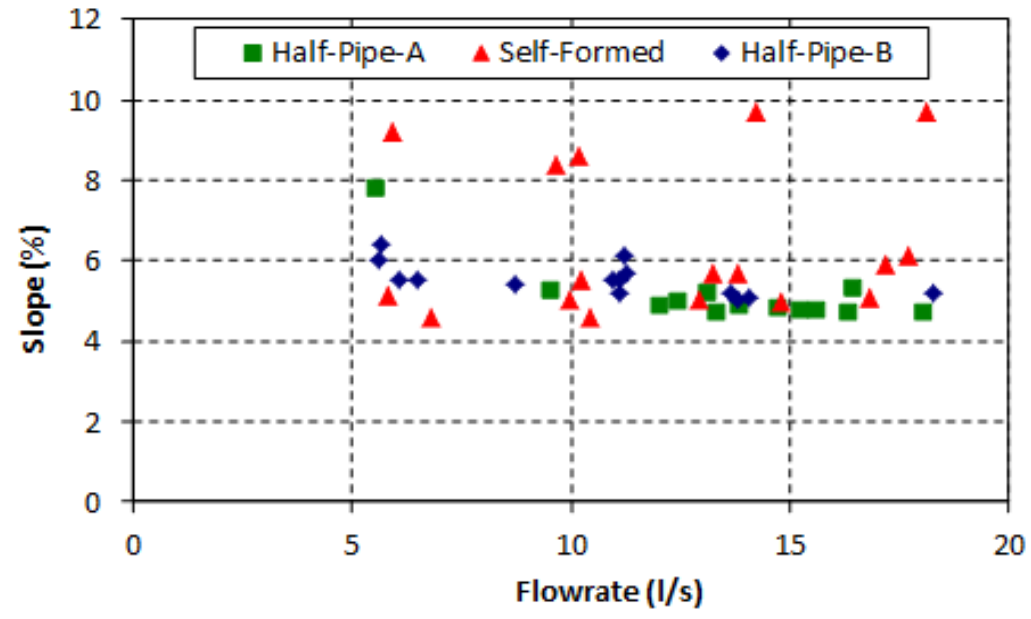

Figure 13 Variation of equilibrium slope with slurry flowrate

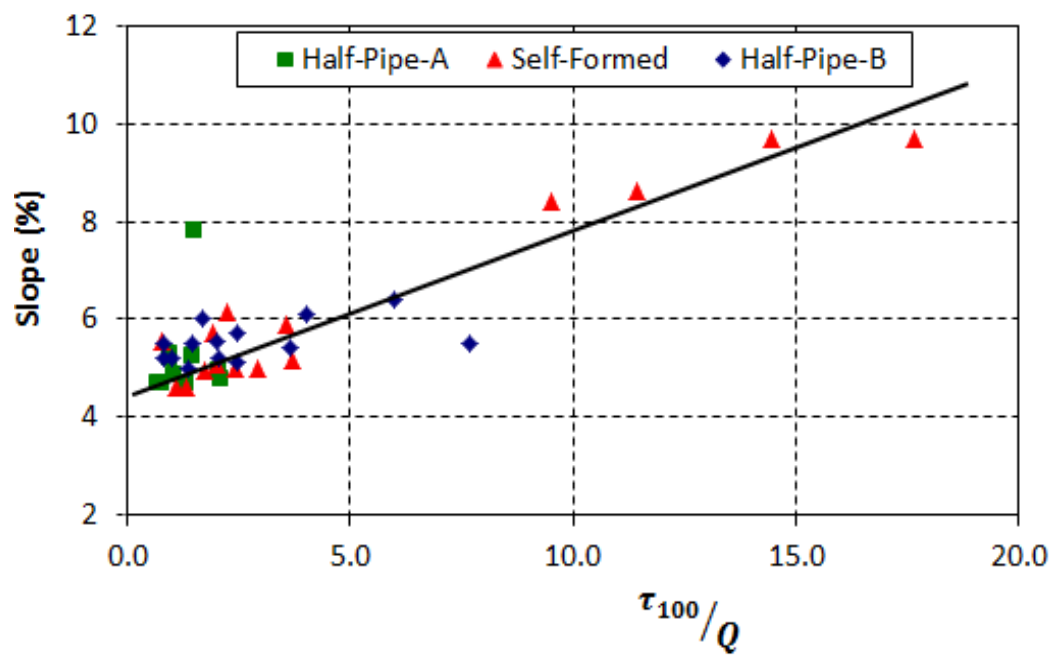

Figure 14 Variation of equilibrium slope with yield stress to flowrate ratio $\left(\tau_{100} / Q\right)$ 


\section{$5 \quad$ Conclusions}

The following direct conclusions and remarks are derived from the observations and analysis of the data recorded during Chuquicamata pilot plant tilt flume testing:

- For the range of slurry solids content tested (56.5 to $72.5 \%$ ) both in self-formed channel and halfpipe channel, the flow condition in the equilibrium channel could not be simply considered as a homogeneous laminar or turbulent flow but instead a plug flow zone appeared at the centreline of the channel with shearing zones close to the stationary boundaries.

- The test results show that the relative width of the plug increases with increase in slurry solids concentration (yield stress). This continues to a point that the shear sub-layer approaches zero thickness and plug width becomes equal to the channel width. In this situation the entire channel flows in a very slow moving laminar regime. Any theoretical model for channel flow analysis should consider this mechanism and the transition.

- The PSD analysis of the samples taken at different time during test works show that the recirculation of tailings slurry using peristaltic pumps has not resulted in break-down of particles and fines generation.

- The PSD analysis on the samples taken from top and bottom of the flow along the flume show that at equilibrium slope, the flow of tailings slurry in self-formed and half-pipe channels could be considered as total transport flow with no segregation or particles sorting.

- The recorded equilibrium slope data suggest that the slope value (i.e. beach slope value) is a complex function of many parameters such as slurry flowrate, rheology, solids content, PSD, etc. Some of these parameters are not independent but the study of the tailings beach slope needs to consider the combined effects of all these parameters.

- Direct scaling from the flume data to real size stack should be avoided. Instead theoretical models such as Pirouz and Williams (2007) and Fitton et al. (2007) which consider the combined effects of all different parameters are required for the prediction of full scale tailings beach slope. The tilt flume data could be used for calibration and verify of the model.

- The open channel flow of concentrated tailings is a growing field of science and there are very limited theoretical models and experimental data available on the subject. This has been described by Abulnaga (2002) as "a topic which is well worth further research". Slatter (2011) has presented some of the progress that has been made on the subject as part of the ongoing recent research works but he has also stated that the "flow model for open channel flow of thickened slurries is still under development".

- The data collected during the variable slope flow-through flume testing which are presented in this paper have been used in conjunction with theoretical models for assessing the achievable tailings beach slope.

\section{Acknowledgement}

The authors would like to acknowledge Codelco for their support during the pilot plant test works and for their permission to publish the data in this paper.

\section{References}

Abulnaga, B.E. (2002) Slurry Systems Handbook, Mazdak International Inc., New York, McGraw-Hill, pp. 6.42-6.43.

Fitton, T.G., Williams, M.P.A., Seddon, K.D., Bhattacharya, S.N. and Chryss, A.G. (2007) Simulation of thickened tailings stacks, in Proceedings Tenth International Seminar on Paste and Thickened Tailings (Paste07), A.B. Fourie and R.J. Jewell (eds), 13-15 March 2007, Perth, Australia, Australian Centre for Geomechanics, Perth, pp. 305-313.

Hedstrom, B.O.A. (1952) Flow of plastics materials in pipes, Industrial and Engineering Chemistry, Vol. 44, No. 3, pp. $651-656$. 
Pirouz, B. and Williams, P. (2007) Prediction of non-segregating thickened tailings beach slope - A new method, in Proceedings Tenth International Seminar on Paste and Thickened Tailings (Paste07), A.B. Fourie and R.J. Jewell (eds), 13-15 March 2007, Perth, Australia, Australian Centre for Geomechanics, Perth, pp. 315-327.

Pirouz, B., Kavianpour, M.R. and Williams, P. (2005) Thickened tailings beach deposition, field observations and full-scale flume testing, in Proceedings Eighth International Seminar on Paste and Thickened Tailings (Paste05), R.J. Jewell and S. Barrera (eds), 20-22 April 2005, Santiago, Chile, Australian Centre for Geomechanics, Perth, pp. 53-72.

Slatter, P.T. (2011) Pipe flow, Rheology Workshop Presentations, Paste and Thickened Tailings Seminar, April 2011, Fremantle, Australia, Section 6.

Williams, M.P.A. (2001) Tailings beach slope forecasting a review, High Density and Thickened Tailings Conference, Pilanesberg, South Africa.

Williams, M.P.A. and Meynink, W.J.C. (1986) Tailings beach slopes, Workshop on Mine Tailings Disposal, The University of Queensland, August 1986, pp. 30-61. 